\title{
Collaborative Design for Young Children with Autism: Design Tools and a User Study
}

\author{
D.Scott McCrickard ${ }^{1}$, Troy D. Abel ${ }^{2}$, Angela Scarpa ${ }^{3}$, Yao Wang ${ }^{1}$, Shuo Niu ${ }^{1}$ \\ ${ }^{1}$ Department of Computer Science, Virginia Tech \\ ${ }^{2}$ School of Visual Arts, Virginia Tech \\ ${ }^{3}$ Department of Psychology, Virginia Tech \\ Blacksburg VA 24061 USA \\ \{mccricks, tabel, ascarpa, yxw5167, shuoniu\}@vt.edu
}

\begin{abstract}
This paper provides an overview of a collaborative design effort that involves computer scientists, psychologists, and designers working together to investigate design methods to help in the creation of technology for people with neurodevelopmental disabilities. The focus of this effort was in developing techniques to help novice designers create technology interfaces to support anger management in young people with autism spectrum disorder (ASD). The primary output for designers is a card set for which each card has a claim about an anger management technique that can help young people. Design activities leveraging scenarios and personas are suggested that leverage the card set in the creation of technology interfaces. This paper introduces the card set and supporting techniques, describes a design session in an undergraduate classroom setting, and speculates about future directions for this work.
\end{abstract}

Keywords-design; human factors; autism; collaboration; anger management; card-based design

\section{INTRODUCTION}

Technology for individuals with neurodevelopmental disabilities is an underserved market in dire need of successfully and thoughtfully designed systems. However, the small population size and the lack of knowledge about the strengths and limitations with regard to people with neurodevelopmental disabilities means that technology needs often are not serviced by the en-masse designed systems of today's culture. The technology currently employed for this population is highly customized and often expensive, driven by a dedicated group of developers who are often employed in small companies or academic settings and tend to work in a siloed model without the opportunity to acquire and share design knowledge. Instead, what is essential is a merging of ideas from technology experts and from domain experts, bringing together the expertise necessary to create welltargeted products.

The goal of this research is to develop technology design approaches targeting people with cognitive and neurodevelopmental disabilities and their network of supporters. The research effort was spearheaded by a workshop at the Designing Interactive Systems (DIS) 2012 Conference [19,20]. This paper represents a stage in this research effort, focusing on designing for autism, a disability that includes impairments in social functioning, communication, and repetitive behaviors, interest, or activities [1]. About 1 in 68 children are affected with an autism spectrum disorder (ASD) in the United States [3]. However, experts in technology and technology design generally will not have expertise in designing for people with autism. This work seeks to provide a means for technology designers to gain insight into possible technological interventions that may help people with autism-providing designers with a starting point for their designs.

Specifically, our approach leverages the Stress and Anger Management Program (STAMP), an evidence-based intervention that features tools to help 5-7 year-old children with autism deal with anger and anxiety management [29,30]. STAMP focus on emotion management can be a stepping stone to addressing other behavioral issues with underlying emotion dysregulation. While the STAMP method is tailored for a series of therapist-led sessions with no defined role for technology, this research effort proposesthat aspects of the method could be adopted or adapted for use in technological solutions that augment the goals of the original program.

This paper focuses on one approach to help technology designers find promising paths to help teach emotion regulation to young children with autism. Specifically, this work considers how undergraduate computer science majors can augment their budding interface design techniques through a focus on supporting people with disabilities. A core challenge in the fields of human-computer interaction and interface design lies in understanding the target user population. Few novice user interface designers have sufficient knowledge about autism, resulting in unrealistic prototypes. It is hard to connect directly to domain experts, and professional papers and the like are often inaccessible to people unfamiliar with the domain. This research effort captures some of the core lessons from STAMP in a set of designer-digestible cards, with a claim about a technique on one side and a representative image on the other. Building on prior successes with similar card-based design approaches in other domains, this paper explores how STAMP lessons can be captured in the card set and shared with technology designers in a way that encourages both creative thinking and grounded solutions. This paper describes the stages in creating this card set, describing its use in an educational setting. 
This paper represents the first step in an effort to share design knowledge about cognitive and neurodevelopmental disabilities. We chose to focus on young people with Autism Spectrum Disorder (ASD) initially, as there are many unique and common behavioral features that appear in children. We expect this work to enable sharing of design ideas not only within the community of people designing for ASD, but across other disabilities — creating opportunities to share design ideas toward supporting multiple disabilities.

\section{RELATED WORK}

Technology has the potential to make an enormous difference in quality of life for people with disabilitiesparticularly young people in the developmental part of their lives. However, poorly-designed or ill-targeted technology could incur significant cost with little or no benefit in a population that can ill-afford it. The work described in this paper examines ways in which informed design with a focus on capturing and sharing knowledge about the target user population can lead to more appropriate designs. This section focuses on user-centered design methods that seem particularly well-suited for designing technologies for people with cognitive and neurodevelopmental disabilities.

One area of guidance for technology designers is in the identification of guidelines, methodologies, and standards for interface design (e.g., [31]). Attempts at formalizing standards, structure, and validation methods for interaction design, such as the International Organization for Standardization (ISO) document ISO 9241-110 (commonly referred to as Part 110), can result in large and unwieldy documents, like ISO 9241-110's 22 pages that presents, “...ergonomic design principles formulated in general terms (...without reference to situations of use, application, environment or technology) and provides a framework for applying those principles to the analysis, design and evaluation of interactive systems" [11]. ISO standards lack of adaption in the majority of US industries, including IxD and HCC, are perhaps rooted in an individualistic confidence in designers' contributions to a problem solution. Moreover, the ISO standards are not readily accessible to the average designer and typically are only incorporated by those practicing in a government entity that requires compliance.

One drawback to this rule-centered approach is that assumptions must be made about an equality of skills in a target population, which can result in the marginalization of populations with different needs. Techniques like the cognitive walkthrough encourage the evaluator to focus on the cognitive steps that a target user would encounter rather than any single rule [14]. The introduction of heuristics can encourage reflection about design principles [25], particularly when are often tailored to match a specific domain or population (e.g, large displays [32,33]). Both cognitive walkthroughs and heuristics seek to provide a technique over capture knowledge.

These types of expert guidance provide general methods for evaluation, but they do not encourage design for specific domains. One method for conveying design concerns toward inspiring design is to capture them on card sets, in which each card focuses on a key concern that should be considered in the design process using images, figures, and text. This presentation style has been shown to be effective in promoting discussion within design teams about the card content [9]. Card sets have been developed for specific technology domains and design concerns (e.g., notification systems [42] and environmental issues [24]), and they have been used in industry, consulting, and academia (e.g., IDEO's method cards [10], von Oech's whack pack [27], Larsson's context cards [13], Tholander's body cards [35] —and our own PIC-UP card set, that resulted in knowledge cards to assist designers of notification systems $[21,42,43])$.

Card-based approaches to technology design can inspire design, but if not created with caution they can suggest a false level of confidence or "truth" in an idea in all contexts, when it may not be universally true. For example, a STAMP technique-singing a song when angry-may have been shown to be effective for young children in certain settings, but it may not be true for older children, or in a non-therapy situation, or for people with a different cultural background. This is particularly important to consider when designing for neurodevelopmental disabilities like autism, for which the skills and limitations of people may vary greatly. Prior work has shown that cultural differences can result in differences when designing for people with autism [2].

To address this issue, information is presented in the form of claims. A claim is a lightweight knowledge representation that encapsulates positive and negative tradeoffs of design features [3,38]. Together with a representative image, claims have shown promise in encouraging creative but well-grounded design $([10,23,43])$ and in making connections between knowledge chunks (e.g., [6, 7,22, 36]. A claims library stores claims and maintains relationships between claims to encourage designers to imagine how disparate ideas can be combined together [39]. Claims libraries have been speculated and created previously (e.g., [28,34], but only recently with a highly accessible claims format and associated tools [21].

\section{APPROACH}

The approach described in this section seeks to develop lightweight but effective ways to convey design knowledge to novice designers lacking domain expertise through the use of a card deck of knowledge claims. This approach draws from an approach called STAMP for helping young kids deal with their emotions [18], toward creating a set of claims cards to help further the development efforts of designers in the creation of technologies to help young people with autism. In so doing, it is important to help designers connect the breadth of possible technologies and techniques. A set of cards was generated in a three-iteration design cycle, with input and feedback at each stage from computer scientists, graphic designers, and psychologists.

The resulting card set consists of two types of cards: technique cards and technology cards (see Figure 1). Technique cards capture key activities from the STAMP treatment method that help manage feelings in young children with ASD; e.g., singing an upbeat song or using a thermometerto encourage reflection on the degree of a feeling. The technique cards include both a visual representation and a 
claims-based representation of a concept, to provide an avenue to balance the inspiration with the knowledge. There are eight cream-colored technique cards that are part of this set. Technology cards exemplify the range of technological solutions that a designer could consider, including computerbased standalone or web applications, multipurpose handheld tablets with specialized apps, custom hardware, and even purely analog solutions. There are eight technology cards, colored light green to distinguish them from the technique cards.

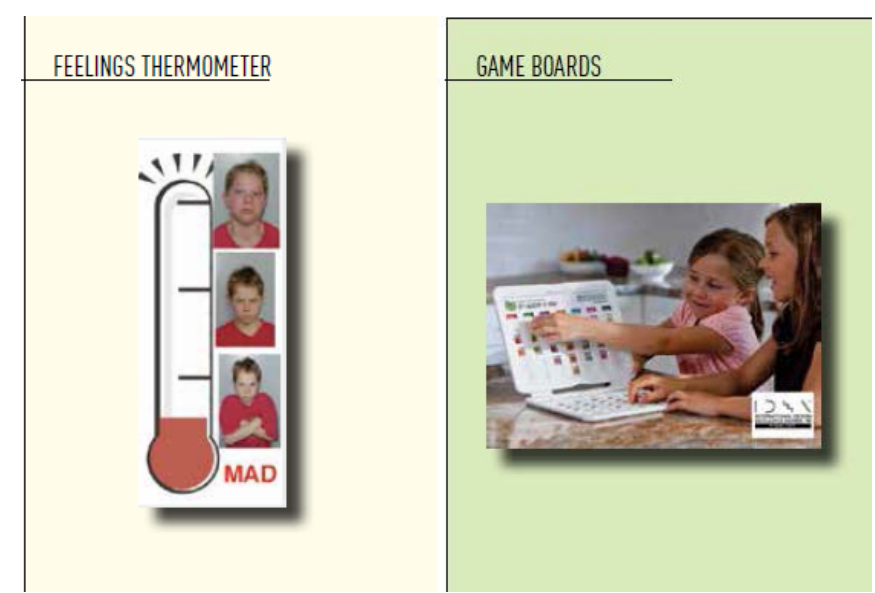

Figure 1: Sample technique (left) and technology cards created to inspire design ideas. The technique cards are augmented on the back with validated claims with 2-5 positive and negative effects regarding the technique; e.g., using a ruler or thermometer to encourage feeling reflection supports creation of "anchor" pictures for feelings, and playing a physically engaging game like musical chairs can frustrate highly competitive children.

To inform and educate designers about their target users, this research developed personas that capture key user characteristics. Personas are archetypes of fictional users that capture important aspects of the needs and desires of a group of users [8]. Personas have been used in assistive technologies situations previously to capture special needs of the elderly, with their visual layout and level of detail contributing to being easy to read and understand [44]. This research resulted in two personas, created and approved jointly by HCI designers and psychologists familiar with autism. "Greg" is a 6-year-old boy in 1st grade, and "Isabel" is a 7-year-old girl in 2nd grade. Both were described as having high-functioning autism spectrum disorder (ASD) with habits and activities typical of children with their backgrounds (see Figure 2 for personas).

Historically there have been lots of ways to use card sets, particularly in the early brainstorming stages of design. This work focuses on one idea development technique often featured as part of HCI techniques and tools, storyboarding $[12,37]$. Storyboards result in a temporal character-focused design centering on the experiences of one or more individuals. For example, a storyboard might focus on Greg becoming angry on the soccer field and needing some time by himself to sing a song that helps him calm down. Figure 3 shows a storyboard from our study.

\section{Greg Martin}

- 6-year-old boy in $1^{\text {st }}$ grade

- his older brother Jeff whom he adores is in $5^{\text {th }}$ grade

- Greg likes Curious George, trains, playing videogames, watching TV, $\&$ being in a 4-on-4 soccer league

- Greg has high-functioning autism spectrum disorder (ASD)

- quickly becomes angry and irritable

- has a few friends but does not like to meet new people

- communicates readily with his parents and brother but few others

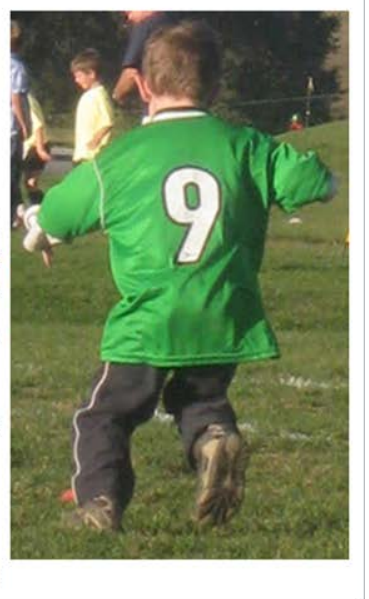

\section{Isabel Ramirez}

- 7-year-old girl in $2^{\text {nd }}$ grade

- Isabel loves reading and math, and she likes to swim

- Isabel collects American Girl dolls and their accessories

- Isabel has high-functioning autism spectrum disorder (ASD)

- quickly becomes angry and irritable

- doesn't transition well to new and unfamiliar activities

- is comfortable with her parents and swim coach but few others

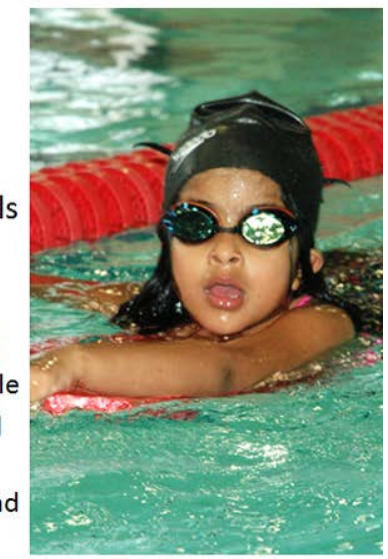

Figure 2: Personas for Greg and Isabel, as distributed to participants in the design activity.

\section{INTERVENTION}

To understand how the cards and techniques might be used by novice designers in an interface design situation, we asked a upper-division undergraduate human-computer interaction class to use them as part of a design activity. The activity was exploratory, seeking to understand whether and how the cards would be used, whether certain cards would be widely used and others ignored, and how the participants would engage in the design task.

To exercise our card set, the classroom study asked students to create a technological design tool that would be helpful in anger management for young people with ASD. This was an in-class activity with potential interest to the human-computer interaction research community. Teams of students in Virginia Tech's CS 3724 undergraduate introductory human-computer interaction class used the cardbased design technique described in this paper to integrate ideas from the cards into a storyboard. All the students had read about and heard in lectures about card decks, personas, and scenarios, but none had more than a few months experience with HCI-related methods. Grades were based on 
attendance only, not on any measure of success. Students were told about this study in class and via email, and they could opt out of up to three activities (including this one) throughout the semester with no penalty. Approval for the study was obtained through the Virginia Tech Institution Review Board (IRB) office (13-375).

\section{A. Method}

The activity asked computer science students to design novel technology to help young children with ASD deal with volatile emotions. The activity consisted of three phases: an assimilation and brainstorming phase in which participants looked at and read over the card set and two personas to gain ideas and inspiration, a storyboarding phase in which participants created a storyboard that described one promising technique from their brainstorming, and a reflection phase in which participants used the ideas to create a storyboard illustrating a new technology and technique.

In the assimilation and brainstorming phase, all participant teams were provided the card set described in the previous section, consisting of eight technique cards and eight technology cards. The participants were told that the cards were to be used to assist in the design of a new intervention technology to be used by a child, the child's parents, and/or the child's counselor. They were asked to consider what the technology might look like, and how each of these key stakeholders might interact with the technology. To encourage broad consideration of the ideas on the cards, they were distributed evenly across team members. They were asked to take a few moments individually to consider the ideas on their cards, then to think about designs that include the elements from at least 2 technology and at least 2 technique cards from the collection of cards. Then as a group, they were asked to develop a set of the most promising ideas. They were asked to come up with multiple ideas, with no upper limit on the number of ideas they developed.

In the storyboarding phase, each team refined their technique, describing it in a six-panel storyboard. The storyboard featured both drawings and captions for each panel. The activity asked that the students familiarize themselves with the two personas described in the previous section, Greg and Isabel, selecting one as the target for the storyboard. In completing the storyboard, students were asked to ensure that at least 3 panels show their interaction technique in use with the novel technology that were envisioned-capturing the things that people see or do with the technology.

In the reflection phase, teams wrote a short report in class about the decisions that they made in creating the storyboard. They were asked specifically to reflect on the inspirations gained from the cards, reasons for selecting cards or ideas for their design, and justification for why the design was promising. All materials were submitted by the end of the 75minute class session. Grades were based on attendance only, not on any measure of success or time taken in the design process, to emphasize creativity and novel directions. Students were told that they could opt out of the activity at any time with no grade penalty.
It was suggested to students that they spend about 20 minutes on initial brainstorming phase, about 25 minutes on the storyboard creation phase, and 15 minutes on reflection and authoring the report. However, these times were only suggestions-they were not enforced in any way. The participant teams were asked to review an information sheet, fill out a 1-page brainstorming sheet, complete a blank 6-panel storyboard template, and author a 1-page final report.

TABLE I. USAGE OF TECHNIQUE CARDS (TOP) AND TECHNOLOGY CARDS (BOTTOM). THE PAIRINGS COLUMN SHOWS WHICH CARDS WERE PAIRED WITH THE FEATURED CARD ACROSS ALL BRAINSTORMED IDEAS, WITH FREQUENCY OF PAIRINGS IN PARENTHESES. GENERALLY PARTICIPANTS PAIRED TECHNOLOGY CARDS WITH TECHNIQUE CARDS, BUT THERE ARE SOME INSTANCES OF PAIRINGS WITHIN TYPE (E.G., TWO TECHNIQUES PAIRED).

\begin{tabular}{|c|c|l|}
\hline Card & Frequency & \multicolumn{1}{c|}{ Pairings } \\
\hline $\begin{array}{c}\text { Feelings } \\
\text { thermometer }\end{array}$ & 18 & $\begin{array}{l}\text { Tablet (10), Multi (2), Keyboard (2), } \\
\text { Game (2), Analog \& digital (2) }\end{array}$ \\
\hline $\begin{array}{c}\text { A physically } \\
\text { engaging game }\end{array}$ & 10 & $\begin{array}{l}\text { Personify (1), Boards (3), E-game (2), } \\
\text { Analog (2), Multi-game (2) }\end{array}$ \\
\hline Body trace & 8 & $\begin{array}{l}\text { Tablet (3), E-game (1), Boards (1), } \\
\text { Analog (2), Analog \& digital (1) }\end{array}$ \\
\hline $\begin{array}{c}\text { Sing an upbeat } \\
\text { and engaging } \\
\text { song }\end{array}$ & 14 & $\begin{array}{l}\text { Personify (3), Game (2), Multi-game } \\
\text { (2), Analog \& Digital + Keyboard(1), } \\
\text { Questions(1), Analog (2), Keyboard } \\
\text { (2), Analog \& digital (1) }\end{array}$ \\
\hline $\begin{array}{c}\text { Ask engaging } \\
\text { questions }\end{array}$ & 9 & $\begin{array}{l}\text { Tablet (2), Personify (2), Boards (2), } \\
\text { Song (1), Analog \& digital (1), Multi- } \\
\text { game (1) }\end{array}$ \\
\hline $\begin{array}{c}\text { Squeeze a lemon } \\
\text { Tablet (1), Boards (1), Game (2), } \\
\text { Analog \& digital (5), Analog (1), } \\
\text { Keyboard (1) }\end{array}$ \\
\hline $\begin{array}{c}\text { Breathe deeply or } \\
\text { meditate }\end{array}$ & 11 & $\begin{array}{l}\text { Tablet (1), Boards (2), Analog \& } \\
\text { digital (1), Analog (3), Keyboard (3) }\end{array}$ \\
\hline Use tools & 13 & $\begin{array}{l}\text { Tablet (2), Game (3), Multi-game (2), } \\
\text { Analog (3), Keyboard (2), Analog \& } \\
\text { digital (1) }\end{array}$ \\
\hline
\end{tabular}

\begin{tabular}{|c|c|c|}
\hline Card & Frequency & Pairings \\
\hline Tablet & 20 & $\begin{array}{l}\text { Thermometer (10), Trace (3), Questions } \\
\text { (2), Meditate (1), Tools (2), Game (1), } \\
\text { Squeeze (1) }\end{array}$ \\
\hline Personify & 7 & Game (1), Song (4), Questions (2) \\
\hline Game boards & 12 & $\begin{array}{l}\text { Game (3), Questions (2), Squeeze (1), } \\
\text { Meditate (2), Trace (1), Thermometer } \\
\text { (2), Song (1) }\end{array}$ \\
\hline $\begin{array}{l}\text { Portable } \\
\text { electronic game } \\
\text { (e-game) }\end{array}$ & 9 & $\begin{array}{l}\text { Game (2), Trace (1), Song (1), } \\
\text { Squeeze(2), Tools (3) }\end{array}$ \\
\hline $\begin{array}{l}\text { Multi-game } \\
\text { portable }\end{array}$ & 8 & $\begin{array}{l}\text { Game (2), Thermometer (2), Song (2), } \\
\text { Tools (1), Questions (1) }\end{array}$ \\
\hline $\begin{array}{c}\text { Analog \& } \\
\text { digital }\end{array}$ & 11 & $\begin{array}{l}\text { Thermometer (2), Keyboard + Song (1), } \\
\text { Meditate (1), Song (1), Squeeze(3), } \\
\text { Tools (1), Trace (1), Questions (1) }\end{array}$ \\
\hline Analog & 13 & $\begin{array}{l}\text { Trace (2), Game (2), Song (1), Squeeze } \\
\text { (2), Meditate(3), Tools(3) }\end{array}$ \\
\hline Keyboard & 15 & $\begin{array}{l}\text { Thermometer (2), Song (6), Squeeze(2), } \\
\text { Meditate(3), Tools(2) }\end{array}$ \\
\hline
\end{tabular}

\section{B. Results}

The activity took place during a 75-minute class session, with a 15-minute introduction and the remainder of the time for the three work phases. 80 students participated in the activity, divided into 26 groups of 3 or 4 . All were computer science majors or minors, and all were between the ages of 18 and 23 . 
The 26 groups generated an average of 5.2 ideas in their brainstorming portion of their design activity (minimum 1, maximum 16). Even though only one group used all of the technique cards during the brainstorming phase, collectively all technique cards were used at least 8 times each. The most frequently used card- Feelings thermometer —was used 18 times, with a mean card usage of 11.6. Usage of technology cards varied to a greater degree, ranging from 7 to 20 with a mean of 11.9 and a median of 11.5. Table 1 shows the distribution and pairings for each of the cards.

Each team created a storyboard leveraging one or more idea from the brainstorming session. All of the storyboards filled the six panels, with all teams following the characterfocused temporal nature that is definitive of storyboarding. Multiple reviews of the storyboards revealed that it was obvious which techniques and technologies were in use in each storyboard. An example storyboard is shown in Figure 3.

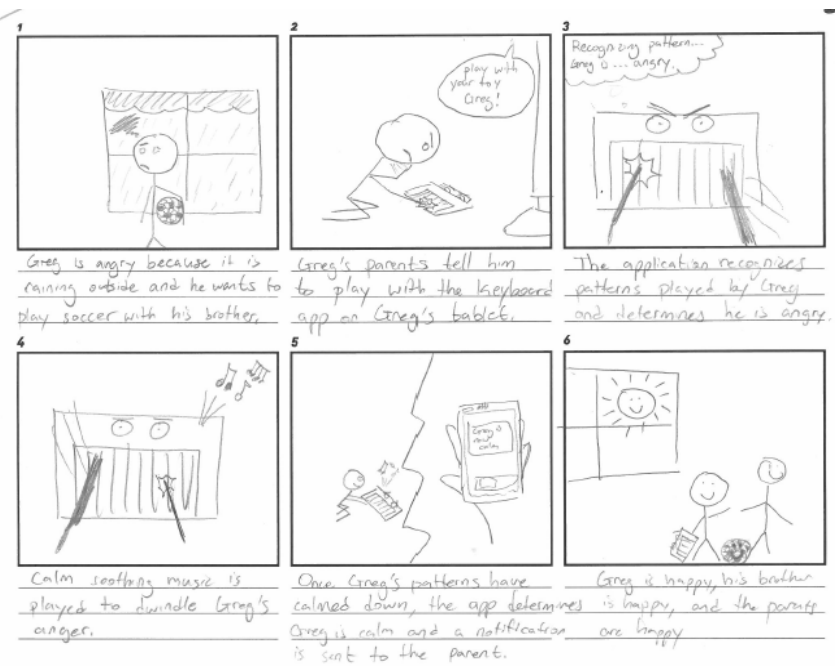

Figure 3 Group C’s 6-panel storyboard, demonstrating how a technological solution could augment and partially automate the established use of music to help in anger management.

Each team authored a report that reflected on their design process, focusing on their use of the card set, their selection of a persona, and their development of techniques. The reports pointed out some strengths and weaknesses of the card set. The groups noted that the cards "gave us general ideas for approaches to autism therapy", with the cards serving as "a starting point for brainstorming" and "were helpful in creating ideas". However, groups also found that the cards "gave off the illusion of constraints" with the feeling that "we could only use the techniques and technology presented on them". A group noted that "some cards were not clear" and "we became entrenched in figuring out” their meaning. One group sums up what seems to be a common feeling by noting: "The cards helped at first, but they became a burden.”

From the reports, it seems the selection of Greg as the lead persona was generally made for personality reasons, "because he likes video games" and "his frustration issues" like "he quickly becomes angry". In summary, a group noted that "his problems were easiest to handle". A few groups mentioned that he seemed like a good match for the techniques and technologies, "with our given set of resources and techniques" and as a match for their own emerging ideas. One group went as far as to start with their own idea, "making something to hit”, and then connecting card ideas to that starting point.

In the reports, the participants indicated that they paired cards that they viscerally believed were good matches, seeking to "create the most viable product" and "pair ideas that went well together". Little rationale was provided beyond vague phrases like "being ideal” or "synergized well”.

\section{DISCUSSION}

The experiment results were encouraging in that the participants leveraged the validated ideas on the technique cards while integrating them with their own knowledge about technology. Each team completed a full early design cycle, resulting in a storyboard representing a reasonable scenario of use for novel technology by young people with autism.

Less encouraging was the low quantity of idea generation, as brainstorming techniques generally result in a great many more ideas even for so short a session. It is difficult to ascertain whether the low number of ideas is due to the techniques used, or novice designers' reluctance to generate ideas at a rapid pace. However, future iterations of the methods should seek to encourage more ideas-particularly given the state goal to target novice designers.

It was a pleasant surprise that all technique cards were used collectively by the six teams; indeed, collectively all technique cards were used at least five times. An initial concern in developing the card deck was that only a select few cards would be used in the designs-ideas that were immediately viewed as the most popular or promising, passing up on ideas that were a better fit but that might require more thought or work. This did not come to pass, but it must remain a concern as the card decks grow in size and quality.

Use of the technology cards results varied more, but that was expected as they were meant to encourage breadth of thought in a known domain rather than to encourage full coverage. Indeed the design teams identified technology-based solutions and non-technology ones, as well as ones rooted in traditional computing devices (e.g., laptops, tablets) and custom-created ones. In future iterations of the card decks, it would be useful to ensure that the technology cards represent the range of technological possibilities along multiple dimensions; e.g., digital to analog, traditional to custom, various media inputs and outputs.

Participants embraced the concept of combining ideas, though it was disappointing that very few wove together multiple techniques in their solutions. Perhaps this was a limitation from the time restriction, or perhaps the activity instructions could have encouraged such behavior more explicitly. The results suggested that participants were able to make the technique ideas their own, though many suggested that the cards became constraining as the activity progressed.

It should also be noted that groups overwhelmingly chose Greg over Isabel as the featured persona in their storyboards. Multiple groups indicated that they focused on Greg because 
his anger and frustration issues seemed easiest to address. Other reasons for the choice stem from the large percentage of males in the study-it seems like Greg's male-centric hobbies and activities appealed to the participant set, or perhaps some aspect of his personality resonated with participants, such as his love of video games and his expressions of strong emotion.

Several general observations emerge with regard to the effectiveness of this design approach. It was encouraging that participants employed all of the techniques in their designs, with consideration for all of the technologies. Feedback from five of the reports indicated that the cards helped with early idea generation as a starting point, but several reports followed up that later in the process the cards seemed restrictive to the design. The quantity of information on each card continues to be a point of debate: too much and designers may not assimilate the most important aspects, but too little and designers may lack necessary details. For example, several group reports indicated that the lack of description for technology cards led them to off-topic discussions about their meaning. There were no comments in the reports regarding the breakdown of visual (pictorial) and textual elements of the cards; it is encouraging that the pictures did not distract from the design process, but there was no particular advantage that was noted for having them.

\section{CONCLUSIONS AND FUTURE WORK}

This paper presents a new design card set and other materials targeted for the creation of new technologies to help young people with autism spectrum disorder (ASD). An investigation of the use of the materials by 24 undergraduate human-computer interaction students showed promise in helping designers brainstorm potential technological aids for young people with neurodevelopmental disabilities.

The materials described in this paper represent a starting point for a larger set of design materials, and the methods represent possible approaches in designing for ASD and other similar disabilities. Moving forward, the overarching task is to seek to balance what's right and best to communicate to designers, providing enough information and perhaps hiding or obfuscating less important and more detailed information through paths that the designers can follow as needed. To accomplish this, it is valuable to consider improvements and expansions to the technique cards, the technology cards, and the persona set. As the material set expands, it is expected that the types of activities for which they are used will expand as well.

The technique cards were extracted from established practices that identified ways to help young people ages 5-7 manage their anger $[29,30]$. As such, it can serve to influence directly the design of technologies to help this population, or to influence thoughts about designs for related populations (e.g., older children, people with different disabilities). Expanding the card set could draw from more proven anger management techniques from the Scarpa work, or from work by others in similar domains, or from hypothesized approaches that researchers surmise might be effective. The number and type of cards that are developed should depend on the target audience of designers, the type of design activity that is planned, and the experience level of the designers.

In expanding and redesigning technology cards, it seems important to think about the dimensions that designers should consider during the design process-e.g., high tech to low (or no) tech, desktop to ubiquitous, solo use to collaborative- - that systematically encourage designers to consider the full range of technological possibilities. By so doing, designers can reflect upon how the role of technology can vary-big and small, visible and invisible - and how the best solution sometimes may not have a major technological component.

In expanding and redesigning the persona set, it is necessary to provide coverage across all personas of the many and varied ways in which ASD can present itself in young people. It was surprising that all study design teams chose the same persona, losing the opportunity to address other needs. Each persona should be compelling to designers, providing a realistic design target that has been shown to motivate designers [8]. Creating a broad and complete persona library necessitates following the lessons from others who have designed personas for people with cognitive and neurodevelopmental disabilities (e.g., [44])—surveying and interviewing the target user group, assimilating data, and testing the persona for appeal and utility.

Broader goals for using cards as design artifacts seek to identify ways to interpret the design context and inspire creative ideas. We notice that even the design question in the experiment is not always familiar and well-understood for the participants, so cards serve as representations of elementary considerations and support the quick capturing of the design space. By discussing, connecting and selecting the collection of the cards, designers gradually evolve the design from uncertain and ambiguous creative forms into a clear and concrete organization of ideas. We believe that exploring and observing the changes of the card structure within these activities provide a chance to unveil the cognitive movement among the design team, since every action on the design card reflects a designer's deliberations of a single or a group of design components towards the ultimate design goal. A deeper analysis of the cardbased design process will offer new methods to understand how designers comprehend the design materials, as well as uncover the usefulness, importance and inspiration-ness of different design elements and discover better pathways to organize and convey the domain knowledge.

Our previous research has identified an initial set of relationships to help categorize card-based design activities [40]. From this work, browsing, workspace organization, and storyboarding are identified as three core sections of card utilization. Combining these categories and findings in this paper, future work will seek to explore and identify a structural understanding of card-based design process. This structure points to enhancement possibilities for card-related design methods, for which situated card-based tools can be provided at different design stages. Also, the collaboration activities for clarifying design ideas might change across different cardbased design stages. Recognizing the patterns of design activities along the design development progress will suggest 
better approaches for card-related operations (such as browsing and organizing).

With increases in large touch-enabled displays, possibilities for using digital cards within shared design spaces presents opportunities and challenges to the card-based design field. Ease of scaling, duplicating, and customizing the cards might be valuable to alleviate the restriction of the paper-based cards, as the flexibility of card appearance enables new possibilities to provide additional design information. Digital cards also enable recording and reviewing of the design progress. Being able to track the evolution of design concepts might be helpful in evaluating the design within and across design stages. However, replacing familiar paper cards with digital ones presents obstacles that require careful consideration. Whether digital cards will retain the advantages of paper cards and support new advantages unique to digital media will require significant future study.

Human understanding seeks organization, structure and schemas upon encountering new instances of knowledge and domain spaces. Through this process, one is able to identify similarities (and differences) which can facilitate rapid search and application [26]. Claims and uncovered knowledge must be taxonomized to facilitate understanding, information retrieval, knowledge accessibility, and broad use. During organization several branches will emerge, each with associated sets of 'leaves,' and 'trunks.' [26] During this process it is imperative to remember these instances occur within a single domain, and often require re-conceptualizing certain instances, while maintaining the understanding that all classification systems are contrived [26]. Appropriate capture and representation of this design information can help shift the design process from a siloed environment to a more collaborative one, broadening the intellectual resources necessary to design a viable, useful, and desirable system. In addition, it can help cross over ideas that are developed target specific disabilities to focus not on disability but on functional difficulty. For example, an older adult recovering from a brain injury may have similar memory or attentional issues to a youth with severe ADD - but the limited ways to share technological successes and failures will result in duplicated efforts, a weaker product space, and slower advancement in addressing the needs of people with disabilities. A broad, inclusive, and accessible knowledge base can help address this limitation.

\section{ACKNOWLEDGEMENTS}

Thanks to members of the Scarpa lab, Virginia Tech's Center for Autism Research, REU students, CS 3724 students, and NSF grants from the EAGER, REU Site, and BPC programs (IIS-1135149, IIS-0851774, CNS-1134960) for their support. Results reflect the authors' contributions and are not necessarily the opinions of these other people or groups.

\section{REFERENCES}

[1] American Psychiatric Association (2000). Diagnostic and Statistical Manual of Mental Disorders. Washington DC: APA.

[2] F. A. Boujarwah, Nazneen, H. Hong, G. D. Abowd, and R. I. Arriaga (2011). Towards a framework to situate assistive technology design in the context of culture. In Proceedings of the ACM Conference on Assistive Technology (ASSETS 2011), 19-26.

[3] J. M. Carroll and W. A. Kellogg (1989). Artifact as theory nexus: Hermeneutics meets theory-based design. In Proceedings of the ACM Conference on Human Factors in Computing Systems (CHI 1989), 7-14.

[4] Centers for Disease Control and Prevention (2012). Prevalence of autism spectrum disorders. Morbidity and Mortality Weekly Report Surveillance Summary 61 (SS03), 1-19.

[5] S. Chandler, J. Harris, A. Moncrief, and C. Lewis (2009). Naming practice for people with aphasia as a mobile web application. In Proceedings of the ACM Conference on Assistive Technology (ASSETS 2011), 247-248.

[6] C. M. Chewar, E. Bachetti, D. S. McCrickard, and J. Booker (2005). Automating a Design Reuse Facility with Critical Parameters. Computer-Aided Design of User Interfaces (CADUI) IV, 235-246.

[7] J. Conklin (2005). Dialogue Mapping: Building Shared Understanding of Wicked Problems. Wiley.

[8] A. Cooper (2004). The Inmates are Running the Asylum: Why High Tech Products Drive Us Crazy and How to Restore the Sanity. Sams Publishing.

[9] S. R. Herring, C. C. Chang, J. Krantzler, and B. P. Bailey (2009). Getting inspired! Understanding how and why examples are used in creative design practice. In Proceedings of the ACM Conference on Human Factors in Computing Systems (CHI 2009), 87-96.

[10] IDEO (2003). IDEO Method Cards [S.I.]: IDEO.

[11] ISO (2006). ISO 9241-110 http://www.iso.org/iso/home/store/ catalogue_tc/catalogue_detail.htm?csnumber=38009. Accessed 2/2015.

[12] J. A. Landay and B. A. Myers. Sketching storyboards to illustrate interface behaviors. In Conference Companion of the ACM Conference on Human Factors in Computing Systems (CHI 1996), 193-194.

[13] A. Larsson, A. Warell, C. Magnusson, and H. Eftring (2011). Dynamic User Experiences Workbook. Available from haptimap.org

[14] C. Lewis, P. Polson, C. Wharton, and J. Rieman (1990). Testing a walkthrough methodology for theory-based design of walk-up-and-use interfaces. In Proceedings of the ACM Conference on Human Factors in Computing Systems (CHI 1990), 235-242.

[15] C. Lewis, J. Sullivan, and J. Hoehl (2009). Mobile technology for people with cognitive disabilities and their caregivers- $-\mathrm{HCI}$ issues. In Proceedings of HCII 2009, 385-394.

[16] S.R. Miller and B.P. Bailey (2014). Searching for inspiration: An indepth look at designers example finding practicies. In Proceedings of International Design Engineering Conference (ASME 2014).

[17] M. B. Rosson and J. M. Carroll (2001). Usability Engineering: Scenario-Based Development of Human-Computer Interfaces. Morgan Kaufman.

[18] A. Scarpa, A. Wells, and T. Attwood (2013). Exploring Feelings for Young Children with High-Functioning Autism or Asperger's Disorder. Jessica Kingsley Publishers.

[19] D. S. McCrickard (2012). Making Claims: Knowledge Design, Capture, and Sharing in HCI. Morgan \& Claypool Publishers.

[20] D. S. McCrickard and C. Lewis (2012). Designing for cognitive limitations. In Proceedings of the ACM Conference on Designing for Interactive Systems (DIS 2012), 805-806.

[21] D. S. McCrickard (2012). DIS 2012: Designing for Cognitive Limitations. Blog post available at http://mccricks.wordpress.com/2012/ 08/22/dis-2012-designing-for-cognitive-limitations/

[22] D. S. McCrickard and C. M. Chewar (2003). Attuning Notification Design to User Goals and Attention Costs. Communications of the ACM 46 (3), 67-72.

[23] D. S. McCrickard, S. Wahid, S. M. Branham, and S. Harrison (2011). Achieving both creativity and rationale: Reuse in design with images and claims. Human Technology 7 (2), 109-122.

[24] L. Nathan, B. Friedman, and D. Hendry (2009). Sustainably ours: Information design as catalyst: Human action and environmental sustainability. interactions 16 (4), 6-11.

[25] J. Nielsen (1994). Heuristic evaluation. In Nielsen and Mack (eds), Usability Inspection Methods. Wiley. 
[26] J. Novak (1998). Learning, Creating, and Using Knowledge. Lawrence Erlbaum Associates.

[27] R. von Oech (2008). A Whack on the Side of the Head: How You Can Be More Creative ( $4^{\text {th }}$ ed.). Warner Books.

[28] C. Payne, C. F. Allgood, C. M. Chewar, C. Holbrook, and D. S. McCrickard. Generalizing Interface Design Knowledge: Lessons Learned from Developing a Claims Library. In Proceedings of the IEEE Conference on Information Reuse and Integration (IRI 2003), 362-369.

[29] A. Scarpa \& N. M. Reyes (2011). Improving emotion regulation with CBT in young children with high functioning autism spectrum disorders: A pilot study. Behavioural and Cognitive Psychotherapy 39 (4), 495500.

[30] A. Scarpa, A. Wells, \& T. Attwood. The STAMP Treatment Manual: Exploring Feelings for Young Children with High-Functioning Autism or Asperger's Disorder. Jessica Kingsley Publishers.

[31] B. Shneiderman \& C. Plaisant (2010). Designing the Uer Interface: Strategies for Effective Human-Computer Interaction ( $5^{\text {th }}$ ed.). Addison Wesley.

[32] J. Somervell and D. S. McCrickard (2005). Better Discount Evaluation: Illustrating How Critical Parameters Support Heuristic Creation. Interacting with Computers (IwC) 17 (5), 592-612.

[33] J. Somervell, S. Wahid, \& D. S. McCrickard (2003). Usability Heuristics for Large Screen Information Exhibits. In Proceedings of the IFIP TC.13 Conference on Human-Computer Interaction (INTERACT 2003), 904-907.

[34] A. Sutcliffe (2002). Domain Theory: Patterns for Knowledge and Software Reuse. L. Erlbaum Associates.

[35] J. Tholander and T. Jaensson (2010). Taking an ethnography of bodily experiences into design - analytical and methodological challenges. In Workshop on Artifacts in Design (part of CHI 2010).

[36] Y. Tian and G. Cai (2014). Modeling claimg-making process in democratic deliberation. In Conceptual Modeling, pp. 458-465.
[37] K. N. Truong, G. R. Hayes, and G. D. Abowd (2006). Storyboarding: An empirical determination of best practices and effective guidelines. In Proceedings of the ACM Conference on Designing Interactive Systems (DIS 2006), 12-21.

[38] S. A. Toulmin (1958). The Uses of Argument. Cambridge Press.

[39] S. Wahid, C. F. Allgood, C. M. Chewar, and D. S. McCrickard (2004). Entering the heart of design: Relationships for tracing claim evolution. In Proceedings of the Conference on Software Engineering and Knowledge Engineering (SEKE 2004), 167-172.

[40] S. Wahid and D. S. McCrickard (2006). Claims maps: Treasure maps for scenario-based design. In Proceedings of the World Conference on Educational Multimedia, Hypermedia, and Telecommunications (EDMEDIA 2006), 553-560.

[41] S. Wahid, S. Branham, L. Cairco, D. S. McCrickard, and Steve Harrison (2009). Picking up artifacts: Storyboarding as a gateway to reuse. In Proceedings of the IFIP TC.13 Conference on Human-Computer Interaction (INTERACT 2009), 528-541.

[42] S. Wahid, S. Branham, D. S. McCrickard, and S. Harrison (2010). Investigating the relationship between imagery and rationale in design. In Proceeings of the ACM Conference on Designing Interactive Systems (DIS 2010), 75-84.

[43] S. Wahid, D. S. McCrickard, J. DeGol, N. Elias, and S. Harrison (2011). Don't drop it! Pick it up and storyboard. In Proceedings of the ACM Conference on Human Factors in Computing Systems (CHI 2011).

[44] B. Wöckl, U. Yildizoglu, I. Buber, B. A. Diaz, E. Kruijff, \& M. Tscheligi (2012). Basic senior personas: A representative design tool covering the spectrum of European older adults. In Proceedings of the ACM Conference on Assistive Technology (ASSETS 2012), 25-32.

[45] Z. Zhang, D. S. McCrickard, S. Tanis, C. Lewis (2012). Supporting employment matching with mobile interfaces. In Proceedings of the ACM Conference on Assistive Technology (ASSETS 2012), 247-248. 